\title{
Conselho de Bioética do INCA (CONBIO)
}

\section{O PROBLEMA}

Em sua reunião do dia 14 de julho de 2008, o CONBIO foi solicitado a analisar e a se pronunciar em questóes relativas a conflitos de interesses, formuladas através de duas perguntas:

1. É recomendável que o INCA mantenha trabalho em parceria com entidades que representam pacientes oncológicos, financiadas pelas indústrias farmacêuticas? 2. É recomendável que profissionais do INCA desenvolvam atividades particulares com estas entidades, eventualmente ocupando funções em seus conselhos?

\section{RESPOSTAS}

1 - Em relação à primeira pergunta, o CONBIO emite o seguinte parecer:

Sim, é recomendável que o INCA mantenha esse relacionamento com entidades da sociedade civil organizada, pois a democracia participativa, estabelecida constitucionalmente para a gestão pública, requer a participação dos vários representantes e instituiçõos da sociedade civil organizada, diretamente envolvida nas políticas e ações de saúde.

A ocorrência de possíveis conflitos e tensões próprios de interesses divergentes entre o preconizado pelas instituições públicas e tais entidades é uma característica das sociedades democráticas contemporâneas, liberais e pluralísticas, e que devem ser solucionados/deliberados no amplo processo dialógico democrático.

Entretanto, para que exista o diálogo entre as partes (ou procura da comensurabilidade e convergência entre interesses) é preciso que todos os interesses envolvidos sejam claramente explicitados pelas partes (transparência).

Ademais, para garantir a preservação da autonomia e a isenção das organizaçōes não-governamentais (ONGs) e do INCA é necessário que sejam observados alguns parâmetros éticos nesse processo de interação e deliberação.

De fato, tem-se assistido a muitas denúncias, veiculadas pela imprensa e não negadas pelo Governo
Federal, de que várias entidades do Terceiro Setor utilizariam recursos públicos sem prestar contas à sociedade, e muitas delas sem atender à finalidade para as quais foram criadas. Com efeito, além de recursos públicos, as ONGs também recebem financiamentos de origem privada, entre eles o da indústria farmacêutica.

Isto não é ilegal, mas pode não ser moralmente correto se envolver conflitos de interesses.

Assim sendo, é exigida tanto a transparência referente à origem e aplicação dos recursos financeiros como o alcance das metas propostas. Em particular, as entidades representativas da sociedade civil (mesmo quando não formalizadas juridicamente) devem explicitar seus objetivos sociais e, acima de tudo, informar claramente quais são as fontes de seu financiamento (origens e valores), independentemente do título que revestem (patrocínio, doação, publicidade etc.). Em nome dessa transparência, a informação deveria ser divulgada amplamente, isto é, não só à administração do INCA, mas também aos usuários e profissionais de saúde que atuam no campo da oncologia.

Por outro lado, o relacionamento com ONGs deve ser preventivamente inibido quando existirem elementos que possam indicar riscos de conflito de interesses incomensuráveis entre as práticas do Sistema Único de Saúde (SUS) e dos financiadores das ONGs. Esse conflito não deve ser considerado genérico e impeditivo de um relacionamento do INCA com a entidade. Deve ser, sim, limitador de seu compartilhamento de fóruns técnicos ou administrativos em que decisões possam direta ou indiretamente - beneficiar ou prejudicar interesses dos que suportam as despesas das ONGs, mas, sobretudo, prejudicar o interesse da saúde pública.

Longe de caracterizar uma discriminação dessas entidades ou um pré-juízo de seus corpos técnicos ou administrativos, a instituição de uma limitação no um 2 - Em relação à segunda pergunta, o CONBIO emite o parecer a seguir:

Há vários conflitos de interesse que podem ocorrer, sendo que o principal é a possibilidade de incompatibilidade entre o exercício da função pública e 
os interesses privados. Neste caso - e como o próprio nome indica - cabe ao servidor "público" servir ao público que deve bem atender, respeitando o Código de Ética Profissional do Servidor Público Civil do Poder Executivo Federal ${ }^{(1)}$, que dispõe:

\section{DAS REGRAS DEONTOLÓGICAS:}

II - O servidor público não poderá jamais desprezar o elemento ético de sua conduta. Assim, não terá que decidir somente entre o legal e o ilegal, o justo e o injusto, o conveniente e o inconveniente, o oportuno e o inoportuno, mas principalmente entre o honesto e o desonesto, consoante as regras contidas no art. 37, caput, e $₫ 4^{\circ}$, da Constituição Federal.

III - A moralidade da Administração Pública não se limita à distinção entre o bem e o mal, devendo ser acrescida da idéia de que o fim é sempre o bem comum. O equilíbrio entre a legalidade e a finalidade, na conduta do servidor público, é que poderá consolidar a moralidade do ato administrativo.

\section{DOS DEVERES:}

i) resistir a todas as pressões de superiores hierárquicos, de contratantes, interessados e outros que visem a obter quaisquer favores, benesses ou vantagens indevidas em decorrência de ações imorais, ilegais ou aéticas e denunciá-las;

t) exercer com estrita moderação as prerrogativas funcionais que lhe sejam atribuídas, abstendo-se de fazêlo contrariamente aos legítimos interesses dos usuários do serviço público e dos jurisdicionados administrativos;

$\mathrm{XV}$ - E vedado ao servidor público;

a) o uso do cargo ou função, facilidades, amizades, tempo, posição e influências, para obter qualquer favorecimento, para si ou para outrem;

g) pleitear, solicitar, provocar, sugerir ou receber qualquer tipo de ajuda financeira, gratificação, prêmio, comissão, doação ou vantagem de qualquer espécie, para si, familiares ou qualquer pessoa, para o cumprimento da sua missão ou para influenciar outro servidor para o mesmo fim;

o) dar o seu concurso a qualquer instituição que atente contra a moral, a honestidade ou a dignidade da pessoa humana;

p) exercer atividade profissional aética ou ligar o seu nome a empreendimentos de cunho duvidoso.

Dessa forma, um profissional vinculado ao INCA não pode, concomitantemente, exercer função diretiva, gerencial ou deliberativa em entidade privada que se relacione com a instituição, ainda que de natureza nãolucrativa, tais como as organizações não-governamentais.

Ademais, no exercício de funções estritamente técnicas opinativas em ONGs (tais como conselhos científicos), o profissional deve ressaltar que suas manifestaçōes exprimem posiçōes particulares, as quais podem não coincidir com as da instituição.

\section{COMENTÁRIO:}

O tema subjacente a ambas as questōes refere-se a possíveis conflitos de interesses ${ }^{(2)}$ entre ONGs, pacientes, poder público (no caso, o INCA) e servidores públicos, referentes à incorporação de novos medicamentos e procedimentos no SUS. O contexto em que o conflito de interesses se inscreve è aquele da problemática da medicalização da sociedade e de suas possíveis conseqüências em termos de saúde pública, como eventuais pressões da propaganda e dos incentivos ao consumo de seus produtos e procedimentos.

A representação da sociedade civil no âmbito da Administração Pública é importante instrumento da democracia participativa, consistindo, no âmbito do SUS, em uma determinação constitucional (art. 198, inciso III). Esse processo - embora voltado à sinergia entre interesses participantes - não se constrói sem conflitos e tensões, próprios de eventuais divergências de interesses legítimos em uma democracia.

Muitas vezes, a discordância refere-se a interesses imediatos, apesar de todos estarem imbuídos da construção mediata de um sistema público de saúde que seja efetivamente universal e integral. É comum, por exemplo, a afirmativa de que há confronto ou incomensurabilidade entre o interesse do paciente - que pretende a cura em curto prazo para seus males - versus o interesse público - que deve ser o de atender a todos

\footnotetext{
${ }^{1}$ Decreto Presidencial no 1.171 de 22 de junho de 1994, disponível em: <HTTP:// Gov.br/ccivil_03/decreto/D1171.htm>, acessado em 29/07/2008.

${ }^{2} \mathrm{Um}$ conflito de interesses surge quando dois ou mais interesses não são comensuráveis entre si, ainda que os interesses não sejam necessariamente incomensuráveis. Os conflitos de interesse são condições nas quais o julgamento de uma pessoa em relação a um interesse específico pode ser influenciado, de forma indevida, por outro interesse. Normalmente, os mais citados e rotineiros são os interesses relativos aos aspectos econômicos, apesar da existência de outros, tais como: os pessoais, os científicos, os relativos à assistência aos pacientes, os religiosos e os sociais. Por exemplo: uma juíza que julgue, perante a Corte, seu filho, tem um conflito de interesses determinado pelo fato de ser, simultaneamente, mãe e juíza (nepotismo), defensora ou protetora do interesse representado pelo bem-estar do filho e, ao mesmo tempo, defensora do "interesse sociopolítico da justiça" ao qual ela está vinculada para poder atuar (to serve) como cidadã e juíza". (Baggini J \& Fosl PS. The Ethics Toolkit. A Compendium of Ethical Concepts and Methods. Oxford UK: Blackwell Publ. 2007: 29).
} 
de forma equitativa e universal, e que pode implicar na restrição de direitos e interesses individuais quando as circunstâncias o exigem.

O elemento essencial para que o diálogo seja franco e construtivo reside na transparência dos objetivos de cada uma das partes, deixando explícitos todos os interesses envolvidos e garantindo que tais objetivos não estejam obliterados por interesses indiretos ou secundários, financeiros ou de outra natureza; ou seja, evitando os conflitos de interesses.

De fato, esses conflitos podem aparecer em várias áreas de atuação, mas a mais relevante, para nós aqui, refere-se à possibilidade de existirem conflitos de interesses na incorporação de medicamentos e tecnologia, baseada em pesquisas envolvendo seres humanos e que envolvem o pesquisador, os sujeitos da investigação, o patrocinador, e a própria sociedade.

No caso sob análise, existe a possibilidade dos pacientes serem induzidos pelas ONGs - e numa instituição pública - a tomarem posiçōes em função da defesa do interesse ao patrocínio da indústria farmacêutica, sem que exista um ganho efetivo, baseado em evidências científicas, para o próprio paciente; podendo, deste modo, haver uma não convergência entre interesses públicos, interesses econômicos e aqueles do paciente. Em suma, há a possibilidade do interesse do patrocinador - ou da dependência financeira em relação a este - influir na autonomia de juízo da ONG ou interferir no seu posicionamento. ${ }^{(3)}$

Entretanto, o fato de existirem vários interesses envolvidos, por si só, não é errado, pois os interesses são, de fato, muitas vezes comensuráveis e convergentes. $\mathrm{O}$ indevido surge quando há mascaramento de interesses secundários sob o manto da legitimidade dos interesses primários (o direito do paciente à assistência). No caso, há conflito de interesse entre querer obter o patrocínio da indústria e - em troca - comprometer-se - voluntária ou involuntariamente - a induzir os pacientes ao uso do produto da própria indústria.

Nesta ponderação, assume relevo, portanto, a questão das fontes de financiamento das instituiçôes e, neste sentido, é indispensável que haja transparência quanto à origem e à aplicação dos recursos financeiros.

Não é, em regra, ilegal ou errado o recebimento, pela ONG, de financiamento da indústria farmacêutica; mas não é moralmente aceitável que:

(1) essa situação seja omitida do conhecimento público, dos representados e dos interlocutores da ONG, bem como

(2) a ONG patrocinada por essas fontes participe dos fóruns em que se discutem ações, políticas ou estratégias que atinjam os interesses dessas empresas.

Ademais, é bom frisar que a saúde pode legitimamente ser considerada como um bem incomensurável - inscrito como tal em vários documentos internacionais sobre direitos humanos - e que, portanto, não poderia - nem deveria - ser tratada como uma simples mercadoria (commodity), cuja finalidade - ou interesse primário - para a indústria é o bem comensurável conhecido como lucro. Mas, neste caso, não se deve esquecer que o interesse da indústria farmacêutica envolve vidas humanas - seus interesses cuja proteção deveria interessar a todos, inclusive aos acionistas, preservando, assim, os vínculos existentes entre economia e ética que garantem a legitimidade moral e social de qualquer política no espaço público.

No caso em exame, quando um paciente é informado somente sobre um aspecto do processo, que diz respeito a seus reais ou supostos interesses como paciente, é fato que ele - ao se posicionar - tomará a decisão baseada em seu conhecimento parcial, que pode ser induzido por quem tiver interesse para tanto e que pode ser divergente do primeiro. Fica, portanto, a dúvida se as ONGs informaram aos pacientes sobre as conseqüências negativas da incorporação de medicamentos não efetivos e, também, se esclareceram aos pacientes que uma eventual quebra de patentes principalmente na área da oncologia - implicaria em forte diminuição de custos para o governo, com a possibilidade de melhoria do atendimento e de acesso a drogas caríssimas para maior número de pacientes, e cujo custo nem sempre é moralmente justificado por razōes efetivamente cogentes frente às reais necessidades de saúde de uma população.

${ }^{3}$ Foi apresentado ao CONBIO estudo realizado por entidade norte-americana (Resolução WHA 61.21: Estratégia Global e Plano de Ação no Domínio da Saúde Pública, Inovação e Propriedade Intelectual) que apurou suposto conflito de interesses em manifestação apresentada por ONGs de todo o mundo perante a 61 a Assembléia Mundial da Saúde, na qual opinavam pela não adoção da política de licenciamentos compulsórios ou quebras de patentes de medicamentos. A pesquisa norte-americana mostrou o dado relevante de que $61 \%$ das ONGs que representam pacientes rejeitaram a proposta, sob a alegação de que os laboratórios perderiam o interesse em pesquisar novas drogas tendo em vista o alto investimento envolvido, com conseqüências nefastas para a própria saúde pública. Levantou-se a hipótese de que os pacientes não sabem dos interesses econômicos implicados nesta questão; que eles ignorariam que os financiadores das ONGs são laboratórios que não irão contra os interesses de seus acionistas diminuindo sua margem de lucro. Das ONGs firmatárias do manifesto, $55,45 \%$ (61 sobre 110) receberiam financiamento da indústria farmacêutica. Três dessas ONGs mantêm relacionamento com o INCA (ABCâncer, ABRALE e Femama). 
Reiterando, o fato de existirem vários interesses envolvidos, por si só, não é errado, mas existem situaçōes em que interesses podem competir entre si, quais sejam: - O interesse particular - legítimo e inalienável - de determinado paciente (ou segmento de pacientes) que quer a cura para seus males versus o interesse público, que deve ser o de atender a todos de forma eqüitativa e universal, e que pode implicar na restrição de direitos e interesses individuais;

- O interesse da ONG na defesa de sua própria existência como representante em princípio legítima dos interesses da sociedade civil versus o interesse da indústria farmacêutica em fazer valer seus interesses de lucro e que podem eventualmente - mas não necessariamente coincidir com interesses humanitários compartilhados pelas ONGs no contexto da defesa e proteção da saúde do ser humano;

- O interesse do paciente que precisa ter acesso ao medicamento e, para isto, a quebra de patente se revela fundamental versus o interesse das ONGs que, para se manterem institucionalmente, precisam dos laboratórios, devendo retribuir com alguma forma de retorno para a própria indústria;

- O interesse do Estado em atender um número maior de pessoas afetadas por doenças e que, para tanto, precisa lidar com recursos escassos, fato agravado pelo aumento expressivo da oferta e do custo de medicamentos, e o conseqüente interesse em quebrar patentes para poder ampliar o cuidado versus o interesse dos laboratórios em receber os lucros financeiros de seu investimento em pesquisa e produção dos novos medicamentos.

Estes são, em síntese, os conflitos de interesse legítimos ou questionáveis - comumente identificados que podem competir entre si, gerando deveres e compromissos que podem influir no processo de tomada de decisão, implicando em condutas éticas erradas ou pelo menos questionáveis.

Dadas estas premissas, e considerando que o INCA é uma instituição de referência nacional, incumbida de atividades que extrapolam a atividade assistencial, sua missão compreende a assessoria ao Ministério da Saúde na coordenação e formulação da política de oncologia no país. Nesse contexto, deve adotar medidas para garantir que o relacionamento com as ONGs seja desenvolvido sem riscos desnecessários de contaminação por interesses secundários que possam comprometer a tomada de decisão em seus Conselhos assessores e deliberativos (como o CONSINCA). Para tanto, há que se estabelecer uma política institucional em relação às situações potencialmente geradoras de conflitos de interesse.

Entre as medidas possíveis, recomendamos que no processo de seleção das organizaçôes que integram os Conselhos do INCA:

a) Seja solicitada das ONGs uma declaração de ausência de conflitos de interesses e o compromisso de informar todos os detalhes sobre os possíveis interesses envolvidos e as modalidades do financiamento de sua entidade durante todo o período que integrarem os Conselhos, devendo, igualmente, apresentar seus relatórios financeiros relativos ao cumprimento de suas metas periodicamente;

b) O INCA deve examinar as informaçôes disponíveis, inclusive os sites institucionais e examinar a composição, missão e fonte de financiamentos da entidade, bem como todas as informaçōes que são prestadas aos pacientes.

Ademais, no exercício de funçôes estritamente técnicas opinativas em ONGs (tais como conselhos científicos), o profissional deve ressaltar que suas manifestaçōes exprimem posiçōes particulares, as quais podem não coincidir com as da instituição.

Rio de Janeiro, 7 de agosto de 2008.

\section{Fermin Roland Schramm} Coordenador

Rosamélia Queiroz da Cunha Miriam Ventura da Silva Marlene Braz Ligia Auxiliadora de O Py Ester Kosovski

Marlon Alberto Weichert Claudia Azevedo F. G. Rabello Abrão Rapoport Ciro Augusto Floriani Rildo Pereira da Silva Yara Pereira Santos da Silva Carlos José Coelho de Andrade Carlos Henrique Debenedito Silva Regina Célia Rodrigues Canedo 